\section{FIT TO DRIVE? POLICY AND PRACTICE IMPLICATIONS OF ASSESSING FITNESS TO DRIVE IN THE UK}

${ }^{1}$ Nicola Christie, ${ }^{2}$ Oliver Carsten, ${ }^{3}$ Dan Campsell, ${ }^{4}$ Rob Tunbridge. ${ }^{1}$ University College London, UK; ${ }^{2}$ University of Leeds; UK; ${ }^{3}$ Road Safety Analysis, UK; ${ }^{4}$ Consultant, UK

\subsection{6/injuryprev-2016-042156.866}

Background Cognitive impairment caused by illness or injury, or neurodegeneration associated with ageing is likely to increase with an ageing population. There is a need for clear policy and practice in order to support the safe mobility of people with cognitive impairment.

Methods A narrative review of research evidence and current policy in the UK was conducted. This covered evidence on the road safety risk associated with cognitive impairments, research on screening tools and their effectiveness, and clinician's knowledge of guidelines and their confidence in decision making.

Results The assessment of fitness to drive is problematic because there is little good evidence of the safety risk of those who drive with cognitive impairment partly because drivers self-regulate, taking themselves out of the system before they are at risk. Research evidence suggests that universal screening at a given age would not be cost effective because age is not a functional criterion given the variation of cognitive impairment caused by age related diseases in older people. Neuropsychological test batteries for other illnesses and injuries affecting the brain have shown inconsistent results and so their validity for clinical decision making remains questionable. There is a lack of confidence among clinicians about how to advise patients about fitness to drive and few specialist driving assessment centres for them to refer patients to.

Conclusions There needs to be more evidence on the safety risk of people driving with injury or illness affecting the brain. A standard care pathway would help to manage the safe mobility of people with cognitive impairment. A protocol for general practitioners and other health professionals is needed to guide how to discuss fitness to drive with their patients. Research is needed to develop a clinically viable desk based assessment of driving safety. Given the growing number of older drivers there is a need for more specialist driving assessment centres.

\section{PROFILE OF ROAD TRAFFIC INJURIES IN BANGLADESH: IMPLICATION FOR FUTURE INTERVENTION IN LOW- INCOME COUNTRIES}

Abu Taleb, Salim Mahmud Chowdhury, Fazlur Rahman. Centre for Injury Prevention and Research, Bangladesh (CIPRB)

\subsection{6/injuryprev-2016-042156.867}

Background Approximately 1.25 million people died on the world's roads, and another 20 to 50 million sustain nonfatal injuries in 2013. In Bangladesh, the deaths from road traffic crashes are notably high (13.6 per 100,000 population) like other lowincome countries. Road traffic injuries has not yet been addressed comprehensively in Bangladesh despite of high burden. In this study, we aimed to explore the magnitude and determinants of road traffic injuries in Bangladesh.

Methods A community-based active surveillance system covering around 150,000 population was developed in three unions (lowest administrative infrastructure) of a sub-district of Sirajgonj district, Bangladesh in 2005. Every year, four rounds of data are being collected from the each and every households of the surveillance areas. July 2009 to June 2010 data from this surveillance system was analysed for this study.

Results It was revealed that rate of road traffic injuries were significantly higher among adults than children (589.72 and 210.85 per 100,000 population per year respectively). Rate of injuries among male were significantly higher than female (406.92 and 94.29 per 100,000 population per year respectively). Bicyclist (21\%), motorcyclist (17\%), passenger of rickshaw/van (17\%) and pedestrians $(14.9 \%)$ were the most vulnerable road users. Rate of permanent disability due to road traffic injury among adults and children are 4.13 and 1.27 per 100,000 population per year respectively. More than half $(50.1 \%)$ of the victims were on their way to work place. $40 \%$ of the victims lost their mobility due to injury. It was found that almost half $(44.8 \%)$ of the victims were the main income earner of their families.

Conclusion As the socioeconomic structure are almost similar in all low-income countries, so the result of the study could be an insight to the policy makers of low-income countries including Bangladesh to develop realistic and effective intervention strategies to combat the issue.

\section{THE DISPROPORTIONATE RISK OF YOUNG DRIVERS FOR ROAD TRAFFIC INJURY AND FATALITY IN QATAR: EVIDENCE FOR POLICY}

${ }^{1}$ Maggie Awadalla, ${ }^{2}$ Lawrence Tallon, ${ }^{2}$ Ruben Peralta, ${ }^{2}$ Ayman El-Menyar, ${ }^{2}$ Hassan AlThani, ${ }^{2}$ Rafael Consunji. ${ }^{1}$ Public Health Researcher, Cairo, Egypt; ${ }^{2}$ Hamad Medical Corporation, Qatar

\subsection{6/injuryprev-2016-042156.868}

Background Road traffic injury (RTI) rates have been decreasing ${ }^{1}$ but are still the leading cause of death in Qatar. ${ }^{2,3}$ Young drivers (age less than 30) were identified as high-risk for $\mathrm{RTI}^{4,5}$ in Qatar but a systematic review of evidence is needed.

Methods A systematic literature review was conducted on 7 electronic peer-reviewed databases between 2003 - 2015 using predefined search terms in truncation and using Boolean terms, documents from international organisations and grey literature. Retrieved articles were screened using a set of inclusion/exclusion criteria. Data was extracted and secondary analysis done for evidence on the risk of young drivers for RTIs and RTI fatalities.

Results 21 articles met inclusion criteria; 12 retrospective observational descriptive studies, 2 grey literature papers (secondary analysis of data and systematic literature review), 1 cross-sectional study, 1 descriptive study, 1 regression analysis for prediction of RTIs, 1 survey, 1 information note by the World Bank, 1 retrospective literature review and 1 re-meta-analysis paper. 15 papers focused on Qatar solely and 6 compared its data with other countries. There was consistent evidence that young male drivers were more likely to: 1.) use a mobile phone while driving 2.) have more traffic violations than females and older drivers 3.) be involved in a four-wheel drive crash, 4.) avail of ambulance, emergency department or trauma services for RTI 5.) sustain severe injury and death on ejection from a vehicle and be involved in all forms of motor vehicle crashes. The relative risk for road mortality of this group was 10 times higher than the general population.

Conclusions Young drivers in Qatar are at a disproportionate risk for risky driving behaviour, traffic violations, involvement in 4WD crashes, ejection in a crash, severe RTI and mortality. A multi-disciplinary strategy, composed of proven interventions, to reduce this health burden must be implemented as a public health priority. 


\section{REFERENCES}

1 Mamtani R, Al-Thani MH, Al-Thani AA, Sheikh Jl, Lowenfels AB. Motor vehicle injuries in Qatar: time trends in a rapidly developing Middle Eastern nation. Inj Prev. 2012 Apr;18(2):130-2. doi: 10.1136/injuryprev-2011-040147. Epub 2011 Oct 12.

2 Consunji RJ, Peralta RR, Al-Thani H, Latifi R. The implications of the relative risk for road mortality on road safety programmes in Qatar. Inj Prev. 2015 Apr;21 (e1):e105-8. doi: 10.1136/injuryprev-2013-040939. Epub 2014 Jan 28.

3 World Health Organisation. Global status report on road safety 2015: supporting a decade of action: summary 2015.

4 Sivak M, Schoettle B. Mortality From Road Crashes In 193 Countries: A Comparison With Other Leading Causes Of Death. The University of Michigan Transportation Research Institute. Report No. UMTRI-2014-6 February 2014.

5 A Bener, T Lajunenc, T Ozkan, D Haigney. "The Effect of Mobile Phone Use on Driving Style and Driving Skills." International Journal of Crashworthiness 2006;11(5):1-7.

\section{ROAD TRAFFIC INJURIES IN KENYA: A HOSPITAL-BASED SURVEILLANCE STUDY}

${ }^{1}$ Isaac M Botchey, ${ }^{1}$ Yuen W Hung, ${ }^{1}$ Huan He, ${ }^{1}$ Abdul M Bachani, ${ }^{2}$ Hassan Saidi, ${ }^{1}$ Adnan A Hyder, ${ }^{1,3}$ Kent A Stevens. ${ }^{1} J o h n s$ Hopkins International Injury Research Unit, USA; ${ }^{2}$ University of Nairobi, Kenya; ${ }^{3}$ Johns Hopkins Hospital Department of Surgery, USA

\subsection{6/injuryprev-2016-042156.869}

Background Road Traffic Injuries (RTIs) are a leading cause of disability and mortality worldwide with a disproportionate burden in Low-and Middle-Income Countries (LMICs). RTIs account for 3.6 percent of the global mortality burden [1]. Additionally, the risk of death from injuries in LMICs is six times more likely than in High Income Countries (HICs)[2]. RTIs are estimated to be the fifth leading cause of disability-adjusted lifeyears (DALYs) lost by 2030 worldwide[3]. Data defining the burden of injury, risk factors and outcomes of RTIs in LMICs are limited. Our study analyses RTIs seen in the casualty departments at four regional referral hospitals in Kenya.

Methods Electronic-based trauma registries were developed at four regional hospitals in Kenya: Kenyatta National, Thika, Meru and Machakos. Information on mechanism of injury, injury severity, patient outcomes, and patterns of care (pre-hospital and hospital-based) was collected prospectively between January 2014 to September 2015.

Results A total of 6429 patients were enrolled. Patients were predominantly male (78.5\%), young (median age 27.6 years) and arrived mainly by car/taxi (49.4\%), mini bus (18.9\%) or an ambulance (16.2\%). Injuries were common amongst pedestrians $(40.8 \%)$ and passengers $(36.7 \%)$. Seatbelts were used by $7.2 \%$ of passengers. Body regions most commonly injured were the extremities (54\%) and head (22.7\%). The overall mortality rate was $2.2 \%$. Predictors of RTI deaths were moderate head injury [GCS 9-12] (OR 6.4, 95\% CI: 4.0-10.1), severe head injury [GCS $\leq 8$ ] (OR 71.5, 95\% CI: 49.7-102.8), moderate ISS [ISS 915] (OR 3.6, 95\% CI: 2.5-5.1) and severe ISS [ISS > 15] (OR 9.4,95\% CI: 5.7-15.2).

Conclusions RTIs contribute significantly to the burden of disease in Kenya. A renewed focus on addressing this burden through the development of a trauma care system is necessary. Trauma registries can be used as a plausible tool to identify priority areas for quality improvement and injury prevention.

\section{0} BICYCLE ACCIDENTS: A NEW TREND FOR HOSPITAL ADMISSIONS?

Ricardo Mexia, Emanuel Rodrigues. Instituto Nacional De Saúde Doutor Ricardo Jorge Portugal

10.1136/injuryprev-2016-042156.870

Background Bicycle riding is an increasing trend in many countries, so accidents connected with cycling activities are also on the rise.

Data from the National Agency for Road Safety shows that in 2013 there were 1708 victims in accidents where a bicycle was involved, rising from 1405 in 2003.

While most accidents are not reported and do not require healthcare, more severe ones can be a cause for admission in Hospitals. Limb injuries are the most frequent, but chest/abdomen injuries and head injuries are also common.

Methods Data was collected from the Portuguese National Hospital Registry $(\mathrm{GDH})$, where all admissions to hospitals in Portugal are registered and coded with ICD9 codes. We gathered data on all admissions, external cause admissions and admissions for ICD9 E826 code (Pedal cycle accident). We compared data between 2003 and 2013 from all hospitals in Portugal..

Results Between 2003 and 2013 there were a total 7170 admissions for bicycle related accidents (651 average each year).

In 2003 there were 652 admissions related to bicycling accidents, while in 2013 there were 725 (an 11\% increase). Male patients account for $83,4 \%$ of those admissions in 2003 and $87,0 \%$ of those in 2013 . When compared to the total external cause admissions, bicycle related admissions represent $0,57 \%$ in 2003 and $0,42 \%$ in 2013 (a 25,6\% decrease). Comparison on proportions for total admissions also presents a 30,0\% decrease: from $0,060 \%$ in 2003 to $0,043 \%$ in 2013.

Conclusions During the last 10 years there has been an increase in the total number of hospital admissions connected with bicycle accidents and injuries. Potential explanations include an increase in cycling as a radical sport (such as mountain biking or downhill riding) and as daily mean of transportation (mostly in the urban setting), but further studies are required.

\section{BUILT ENVIRONMENT ANALYSIS FOR ROAD TRAFFIC HOTSPOT LOCATIONS IN MOSHI, TANZANIA}

${ }^{1}$ Meredith Waldon, ${ }^{2}$ Treasure Joelson, ${ }^{3}$ Luciano Andrade, ${ }^{1}$ Joao Ricardo N Vissoci, ${ }^{2}$ Mark Mvungi, ' ${ }^{1}$ Catherine Staton. ${ }^{1}$ Duke University, Durham USA; ${ }^{2}$ Kilimanjaro Christian Medical Centre, Tanzania; ${ }^{3}$ Unioeste. Foz Do Iguaçu, Brazil

\subsection{6/injuryprev-2016-042156.871}

Background Road traffic injuries (RTI) are a significant cause of morbidity and mortality in low and middle income countries (LMIC). Further investigations of the high risk areas for RTIs in LMIC are needed to guide improvements in road safety planning. This study aims to provide a built environmental analysis of road traffic crash hotspots within Moshi, Tanzania.

Methods After ethical and police permission, Moshi police data was collected and descriptive statistics were tabulated. Hotspots were identified through spatial analysis and relevant patterns in environmental characteristics determined using Qualitative Comparative Analysis (QCA). 